\title{
SECESIÓN Y CONSTITUCIONALISMO COMPARADO
}

\author{
NÚRIA GONZÁLEZ CAMPAÑÁ
}




\section{SUMARIO}

1. Introducción. 1.1 Secesión y constitucionalismo. 1.2 ¿Deben las Constituciones incluir cláusulas de secesión? 2. El clásico y el nuevo paradigma: Estados Unidos y Canadá. 2.1. Estados Unidos. 2.1.a) Secesión por medio de la revolución. 2.1.b) Secesión a través del consentimiento de los estados. 2.2 Canadá. 2.2.a) Dictamen del Tribunal Supremo de Canadá sobre la aspiración de independencia de Quebec 3. Respuestas a procesos secesionistas en el contexto europeo occidental. 3.1 Reino Unido. 3.1.a) Escocia. 3.1.b) Irlanda del Norte. 3.2 Italia y Alemania. 4. Conclusiones. 5. Bibliografía. 


\title{
SECESIÓN Y CONSTITUCIONALISMO COMPARADO
}

\author{
NÚRIA GONZÁleZ CAMPAÑ Á ${ }^{1}$
}

\section{INTRODUCCIÓN}

\subsection{Secesión y constitucionalismo}

La secesión se ha considerado tradicionalmente un "tabú constitucional”2, ya que desafía algunos de los postulados básicos del pacto fundacional de una comunidad política. Además, durante muchos años se asoció con conflictos violentos. En las últimas décadas, tanto el constitucionalismo canadiense, como algunos órdenes jurídicos europeos se han visto obligados a abordar este asunto. Aunque hay algunas características comunes en la manera de tratar la cuestión, también se detectan particularidades. Desde el punto de vista del constitucionalismo de las democracias liberales consolidadas, que es el centro de atención de este artículo, se pretenden subrayar los rasgos comunes y las diferencias en la manera de tratar la secesión. Así, se analizarán los dos ordenamientos jurídicos considerados como los principales paradigmas liberal-constitucionales a la hora de aproximarse a la cuestión de la secesión en derecho constitucional comparado: por una parte, el estadounidense (que ha sido calificado como el paradigma clásico) y, por otra, el canadiense (denominado el nuevo paradigma). ${ }^{3}$ A continuación, se revisará el ordenamiento jurídico británico, que sigue, aunque con matices, el llamado nuevo paradigma. El caso británico es especialmente revelador, ya que ofrece dos respuestas ligeramente diferentes dentro de un mismo orden jurídico. Se verá que la aproximación constitucional a los casos de

1 Núria González Campañá es doctora en Derecho por la Universidad de Oxford y miembro del Grupo de Estudios sobre Democracia y Constitucionalismo (GEDECO) de la Universidad de Barcelona, grupo consolidado por la Generalitat de Cataluña 2017. Esade Law School, Av. Pedralbes 60-62, 08034 Barcelona. Email: nuria.gonzalez2@esade.edu

2 Mancini, S. (2012). "Secession and self-determination" en Michael, R. y Sajó, A. (eds), The Oxford Handbook of Comparative Constitutional Law, Oxford, Oxford University Press, 494.

3 La referencia a un "nuevo paradigma” en López Basaguren, A. (2014). "Estado democrático y secesión de territorios. Un análisis comparado sobre el tratamiento democrático de las reclamaciones secesionistas”, en Arregi Aranburu, J. (ed), La Secesión de España, Madrid, Tecnos, 51. 
Irlanda del Norte y Escocia no es idéntica. Esto revela que las cláusulas de secesión no son producto de teorías legales abstractas, sino instituciones enraizadas en la historia y en las circunstancias concretas de cada país. Aunque de manera breve, se tendrán en cuenta las posiciones constitucionales sobre esta cuestión en Italia y Alemania, también expresadas recientemente. Se concluirá que, en realidad, el llamado nuevo paradigma no ha venido a sustituir al modo clásico de tratar la secesión, sino que hoy día ambos modelos conviven, puesto que en los últimos años el paradigma clásico (España, Italia, Alemania) ha demostrado su vigencia.

Conviene aclarar los límites del presente trabajo: al tratarse de una investigación sobre la secesión dentro de Estados con regímenes liberal democráticos consolidados, se excluyen las referencias a otras experiencias de derecho público comparado, como pueden ser los ejemplos históricos de países bajo régimen comunista en cuyos textos constitucionales había referencias explícitas a la secesión ${ }^{4}$ o el caso particular de la Unión Europea, con el Brexit y con el debate sobre la permanencia en la organización después de un proceso de secesión en el interior de un Estado miembro. ${ }^{5}$ Se entiende que el análisis de realidades constitucionales tan dispares (Estados compuestos con regímenes liberal democráticos frente a regímenes comunistas, confederaciones o la UE) no contribuiría a obtener conclusiones claras y relevantes, sino que se pecaría de cierto eclecticismo y superficialidad. Así, en este trabajo se sigue el método o principio comparativo de los casos más similares o más próximos. ${ }^{6}$

\section{2 ¿Deben las Constituciones incluir cláusulas de secesión?}

Hay una cuestión previa al análisis de los ordenamientos jurídicos concretos que merece cierto análisis: $\gtreqless$ son las Constituciones los documentos apropiados para incluir cláusulas de secesión? Por el momento, los ejemplos de cláusulas de secesión en textos constitucionales son tan limitados que ofrecen poco valor analítico: sólo los textos constitucionales de Etiopía ${ }^{7}$, Liechtenstein ${ }^{8}$ y las islas caribeñas de St. Kitts \& Nevis ${ }^{9}$ contienen referencias a un proceso de secesión. Es por ello que, la discusión, que no

4 Aunque difícilmente las Constituciones semánticas comunistas pueden asimilarse a Constituciones normativas propias de democracias liberales. Ver Loewenstein, K. (1957). Political Power and the governmental Process, Chicago, University of Chicago Press.

5 En este sentido conviene destacar la siguiente obra colectiva, que aborda al detalle ambas cuestiones, aunque desde una perspectiva del derecho de la Unión Europea, no del constitucionalismo de los Estados Miembros: Closa, C. (2017) (ed). Secession from a Member State and Withdrawal from the European Union. Troubled Membership, Cambridge, Cambridge University Press.

6 Hirschl, R. (2005). "The question of Case Selection in Comparative Constitutional Law". American Journal of Comparative Law, 53, 133.

7 Ver el artículo 39 (4) c) de la Constitución de Etiopía.

8 Ver el artículo 4 (2) de la Constitución del Principado de Liechtenstein.

9 Ver el artículo 113 (2) b) de la Constitución de St Kitts y Nevis. 
es nueva, se centra, sobre todo, en argumentos propios de la teoría y la interpretación constitucionales.

En la década de los noventa, el profesor de derecho constitucional de la Universidad de Harvard, Cass Sunstein, se pronunció al respecto en un artículo que se convirtió en seminal: ${ }^{10}$ más allá de las razones políticas que puedan justificar un movimiento independentista dentro de una democracia consolidada, el derecho a la secesión no debería incluirse en un documento o pacto fundacional como es la Constitución, ya que ello reduce las perspectivas del compromiso. Según Sunstein, este tipo de cláusulas degrada la política ordinaria y, lo que resulta incluso más peligroso, entraña el riesgo de chantaje por parte de determinadas regiones. Su visión es sumamente pragmática: una constitución debe estar comprometida con el éxito de la vida en común. Para Sunstein, el derecho a la secesión es diferente de otras demandas, ya que suscita pasiones relacionadas con el territorio, la historia, la cultura, la identidad... Estas cuestiones tienen una particular capacidad de inflamar a las partes en el debate, lo que dificulta en gran medida la labor cotidiana de la gestión de la cosa pública. ${ }^{11}$

Buchanan comparte esta visión. Para él, los valores de una democracia constitucional van en contra de un derecho a la secesión basado únicamente en la voluntad de la mayoría (la única justificación posible en una democracia avanzada, donde, en principio, situaciones graves de violación de derechos humanos quedan excluidas). Según Buchanan, reconocer tal derecho entorpecería las condiciones necesarias para la consolidación de una democracia sana estimulando comportamientos destructivos y debilitando los incentivos de participar y compartir el destino común. ${ }^{12}$ Así, de acuerdo con Buchanan, que comparte la preocupación de Sunstein, si tal derecho se reconociera, una minoría concentrada en un territorio podría usar la cláusula de secesión como una herramienta de negociación, especialmente si se trata de un territorio con una renta y unas condiciones económicas superiores a la media del país. Es decir, la cláusula de secesión, además de ser un derecho que, a efectos prácticos, se estaría concediendo sólo a aquellos territorios con determinadas condiciones (lo cual sería discriminatorio), podría convertirse en un instrumento de chantaje frente al gobierno central y al resto de entidades sub-nacionales. En España, Tajadura ha subrayado la transitoriedad que una cláusula de secesión otorgaría al texto constitucional: "la inclusión del derecho de autodeterminación en una Constitución colocaría a esta en una posición de norma transitoria, cuya vigencia plena (sobre la totalidad del territorio y la población del Estado) quedaría condicionada a que los titulares del derecho

10 Sunstein, C. (1991). “Constitutionalism and Secession”. University of Chicago Law Review, 58, 633.

11 Ibid. 650-651.

12 Buchanan, A. (1998). "Democracy and Secession”, en Moore, M. (ed), National Self-Determination and Secession, Oxford, Oxford University Press, 21. Sin embargo, Buchanan también admite que quizás, en el caso de circunstancias muy excepcionales, resultaría apropiado un derecho constitucional sometido a un procedimiento con costes especiales, con períodos largos de espera entre las convocatorias de referéndums, con requisitos de súper mayorías, etc.. Ibid. 31. 
de autodeterminación no lo ejerciesen." ${ }^{13}$ Desde un punto de vista de teoría constitucional, además, reconocer un derecho unilateral a la secesión, para Haljan significaría rechazar la necesidad de un proceso deliberativo en que todas las partes que constituyen la nación (no sólo algunas de sus subunidades) tomen parte en la decisión, lo que equivale a abandonar la idea de que es toda la población la que participa en la formación de la voluntad mayoritaria. ${ }^{14}$

Otros autores, sin embargo, han mostrado su disconformidad con esta interpretación. Así, Daniel Weinstock o Wayne Norman consideran que una cláusula de secesión obligaría a los secesionistas a hacer análisis fríos y lúcidos sobre costes y beneficios, precisamente el tipo de análisis a los que son reacios. Además, para Weinstock, y esto para él resulta fundamental, una cláusula de secesión mitigaría las tensiones territoriales porque permite que los ciudadanos de regiones en las que hay claras demandas secesionistas puedan embarcarse en el tipo de debate al que aspiran: aquel que se refiere a las decisiones sobre su propio destino. Weinstock nos recuerda que los símbolos importan, cuánto más en la era de la política de la identidad, y, por ello, entiende que el simple hecho de ofrecer la posibilidad de una secesión pactada haría desaparecer una de las principales fuentes de insatisfacción de los secesionistas: no poder decidir su futuro como pueblo o como nación. ${ }^{15}$ Weinstock también entiende que constitucionalizando la secesión se podría controlar un proceso que, de producirse sin un marco previamente establecido, podría resultar muy perturbador: "las demandas independentistas se plantearán, haya o no un cauce para ellas, lo prohíba la ley o no. Si ocurre en una situación de vacío legal ello puede ser más dañino que si sucede siguiendo unos parámetros previamente establecidos." ${ }^{16}$ Norman, por su parte, señala que "una cláusula de secesión en una Constitución desempeñaría unas funciones similares a las normas electorales o los procesos de reforma. Regularía un ámbito muy particular (fundacional) de la política especificando criterios claros de éxito y fracaso." ${ }^{17}$ En su opinión, algo que también comparte Weinstock, una cláusula de secesión en una democracia avanzada debería aclarar qué tipo de grupos tienen derecho al procedimiento; la pregunta o las condiciones que debería satisfacer la misma en un hipotético referéndum; la entidad que tendría la autoridad para negociar los términos de la secesión; y las exigencias en cuanto a quorum de participación y

13 Tajadura, J. (2019). “La problemática jurídica de la secesión” en Aragón Reyes et altri (dirs), La Constitución de los Españoles, Madrid, Fundación Giménez Abad y Centro de Estudios Políticos y Constitucionales, 311.

14 Haljan, D. (2014). Constitutionalising Secession, Londres, Hart, capítulo 7.

15 Weinstock, D. (2011). "Constitutionalizing the Right to Secede". Journal of Political Philosophy, 9 (2), 201-202.

16 Ibid. 196.

17 Norman, W. (1998). "The Ethics of Secession as the Regulation of Secessionist Politics", en Moore, M. (ed), National Self-Determination and Secession, Oxford, Oxford University Press, 48. 
aprobación del referéndum. ${ }^{18}$ En España, Aláez Corral también se ha mostrado a favor de la inclusión de una cláusula de secesión sujeta a condiciones de ejercicio estrictas. ${ }^{19}$

En cualquier caso, debe subrayarse que este debate se ha circunscrito a ambientes académicos. Aun así, el silencio normativo no ha impedido la elaboración de diversas respuestas constitucionales. A continuación, se hará un análisis de las mismas.

\section{EL CLÁSICO Y EL NUEVO PARADIGMA: ESTADOS UNIDOS Y CANADÁ}

\subsection{Estados Unidos}

En los EEUU, a mediados del siglo XIX, el debate sobre la secesión corría en paralelo a la discusión política sobre la institución de la esclavitud y las demandas de los estados del Sur. En las décadas previas a la Guerra Civil la cuestión sobre si la Constitución permitía a un estado separarse de la Federación constituía un debate apasionante..$^{20}$ Fue John C. Calhoun, representante de Carolina del Sur, quien popularizó la idea de que la Federación estaba, igual que la Confederación, compuesta y legitimada por estados, no por ciudadanos. Los políticos sureños consideraban que si la Unión era un pacto entre partes con iguales derechos y deberes (i.e. los estados), cada estado podía unilateralmente decidir si el resto había violado algunas cláusulas del pacto, como por ejemplo el intento de prohibir la institución de la esclavitud, fundamental para la economía y cultura sureñas, y, en consecuencia, retirarse de la Federación. ${ }^{21}$ En otras palabras, si los estados eran independientes antes de ratificar la Constitución, deberían ser capaces de reclamar y obtener de nuevo su independencia y soberanía. De hecho, en el pasado había habido una amplia aceptación entre la clase política americana del derecho a la secesión unilateral y las amenazas de secesión fueron esgrimidas en varias ocasiones por varios estados. ${ }^{22}$ La propia idea de secesión

18 Ibid. 53-54. Norman también admite que es improbable que los países incluyan este tipo de cláusulas. Si el país no se está enfrentando a demandas secesionistas, se querrá evitar abrir un debate sobre la secesión; si ya hay movimientos independentistas, resultará muy difícil llegar a un acuerdo sobre la cláusula más apropiada. Ibid. 55.

19 Aláez Corral, B. (2015). "Constitucionalizar la secesión para armonizar la legalidad constitucional y el principio democrático en Estados territorialmente descentralizados como España”. Revista d'Estudis Autonòmics i Federals, 22, 163 y ss.

${ }^{20}$ Strauss, D.A. (2001) “The irrelevance of constitutional amendments”. Harvard Law Review, 114 (5), 1486.

21 Benjamin, J.P. (1996). “The right of Secession (December 31, 1860)”, en Wakelyn, J.L. (ed), Southern Pamphlets on Secession. November 1860 - April 1861, Chapel Hill, The University of North Carolina Press, 107-108.

22 Radan, P. (2006). "An Indestructible Union... of Indestructible States: The Supreme Court of the United States and Secession”. Legal History, 10, 196. 
está en el origen de la revolución americana. ${ }^{23}$ Pero la Guerra Civil Americana modificó radicalmente la atmósfera política y selló la discusión. ${ }^{24}$ En efecto, el triunfo militar de la Unión dio por terminado el debate sobre la constitucionalidad de la secesión. A partir de entonces, la secesión quedaría claramente prohibida.

Así, poco después de la Guerra Civil, en 1869, el Tribunal Supremo de los EEUU abordó la constitucionalidad del intento de secesión de Texas en Texas $v$. White. Texas se había integrado en la Unión en 1845 e intentó salirse de la misma en 1861. El principal argumento de la decisión fue que Texas se convirtió en 1845 en parte de una "Unión indestructible, compuesta de estados indestructibles." 25 El Tribunal Supremo recordaba que el Artículo XIII de los Artículos de la Confederación y la Unión Perpetua de 1777 declararon que los Estados Unidos constituían una unión perpetua, mientras que el Preámbulo de la Constitución de 1787 establecía que dicha Constitución se elaboraba "para formar una unión más perfecta." Tal y como señaló el Tribunal, "es difícil trasladar la idea de unidad indisoluble de manera más clara que con estas palabras. ¿Qué puede ser indisoluble si una Unión perpetua perfeccionada no lo es?"26

En los EEUU, la cuestión sobre la constitucionalidad de la secesión ha estado clara desde entonces ${ }^{27} \mathrm{y}$, tal y como Sunstein recuerda, "no hay un solo político o académico serio que hoy defienda que el constitucionalismo americano contiene un derecho a la secesión." 28 De manera resumida, podría afirmarse que el modelo constitucional norteamericano al respecto es simple y llanamente "no a la secesión." ${ }^{29} \mathrm{La}$ respuesta jurídica del Tribunal Supremo actuó "como parteaguas marcando el tránsito de la vieja Constitución de los fundadores al nuevo orden constitucional que emerge de la guerra civil." ${ }^{30}$ No es de extrañar por tanto, que estuviera ampliamente influenciada por el pensamiento político del bando ganador de la Guerra Civil, los estados del norte y su líder, Abraham Lincoln, quien promovía la idea de soberanía federal en lugar de la soberanía de los estados. En su Primer Discurso Inaugural el presidente Lincoln sostuvo que el orden constitucional no es un acuerdo del cual las partes puedan separarse unilateralmente. Un gobierno democrático está basado en la

23 Ryan, E. (2019). "Secession and Federalism in the United States: Tools for Managing Regional Conflict in a Pluralist Society” en López Basaguren, A. y Escajedo San-Epifanio, L. (eds), Claims for Secession and Federalism, Cham, Springer, 15-21.

${ }^{24}$ Paulsen, M.S. (2004). "The Civil War as Constitutional Interpretation”. University of Chicago Law Review, 71 (2), 691.

${ }^{25}$ Texas $v$ White 74 US 700 (1869) 725.

26 Ibid.

27 Decisiones posteriores del Tribunal Supremo siguieron la misma interpretación: White v Hart 80 US 646 (1871) 651; Taylor $v$ Thomas 89 US 479 (1874) 491; Daniels $v$ Tearney 102 US 415 (1880) 418.

28 Sunstein, C. "Constitutionalism and Secession", cit., 633.

29 Ryan, E. "Secession and Federalism in the United States: Tools for Managing Regional Conflict in a Pluralist Society " cit., 11.

30 Ahumada Ruiz, M.A. (2019). "La jurisprudencia de la secesión: Texas versus White en contexto” en Aragón Reyes et altri (dirs), cit., 287. 
voluntad de la mayoría limitada por las normas que se ha dado a sí misma, la Constitución. La secesión debía excluirse del pacto fundacional. De lo contrario se fomentaba la anarquía. ${ }^{31}$

En Texas $v$ White, sin embargo, el Tribunal Supremo reconoció que un estado puede separarse de la Unión a través de una revolución o del consentimiento del resto de estados: "No ha lugar a la reconsideración o la revocación, excepto por medio de una revolución o con el consentimiento de los estados." 32

\section{1.a) Secesión por medio de la revolución}

La idea de la revolución no es, obviamente, extraña a la tradición constitucional americana, ya que la misma fundación del país se basa en una guerra revolucionaria contra un poder colonial. Lo que resulta clave en una revolución es si finaliza con éxito. En 1887 en Williams v Bruffy, al discutir la validez de determinados actos en caso de secesión, el Tribunal Supremo sostuvo lo siguiente: "La validez de sus actos, tanto frente al Estado como frente a sus ciudadanos, depende enteramente de su éxito final. Si fracasa en establecerse de manera permanente, sus actos carecerán de validez. Si tiene éxito y es reconocido, sus actos, desde el inicio, serán reconocidos como los de una nación independiente." ${ }^{33}$

El Tribunal no estaba admitiendo ningún derecho: una revolución es una cuestión de hecho, no de derecho. Tal y como diría más de un siglo después el Tribunal Supremo de Canadá, en un contexto de secesión, lo que importa es el principio de eficacia: "la viabilidad de un futuro estado en la comunidad internacional depende, como cuestión práctica, del reconocimiento de los otros Estados." ${ }^{4}$

\section{1.b) Secesión a través del consentimiento de los estados}

Cuando el Tribunal Supremo se refiere a "consentimiento", ¿qué significa? Puede considerarse que consentimiento se refiere al consentimiento unánime de todos los estados. También podría entenderse como reforma constitucional. ${ }^{35}$ El artículo V de la Constitución americana establece que una reforma constitucional exige ser propuesta por o bien dos terceras partes de ambas cámaras o bien por dos terceras partes de las asambleas legislativas de los estados y se requiere luego la aprobación de tres cuartas partes de los estados, además del Congreso. Es un requisito difícil de satisfacer, pero,

31 Basler, R.P. et al (eds). (1954). Collected Works of Abraham Lincoln, New Brunswick, Rutgers University Press, Vol 4, 256-257.

32 Texas $v$ White, cit., 726.

33 Williams v Bruffy 96 US 176 (1877) 186.

34 Reference re Secession of Quebec [1998] 2 SCC 217, para 142.

35 Pavkovic, A. and Radan, P. (2007). Creating New States, Farnharm, Ashgate, 223. 
según algunas interpretaciones permitiría una vía legal para la secesión. ${ }^{36}$ Así, siguiendo este razonamiento, Texas $v$ White solo considera ilegal la secesión unilateral, pero permitiría aquellas secesiones sometidas a los requisitos de la reforma constitucional. Hay quien, sin embargo, considera que un proceso de reforma constitucional para incluir una cláusula de secesión atenta contra el espíritu de la Constitución americana. De tal modo que una modificación no podría incluir tal cláusula, porque el poder de reforma tiene ciertos límites, a diferencia del poder constituyente. ${ }^{37}$

La constitucionalidad de la secesión ha dejado de ser una cuestión debatida en el constitucionalismo americano. No hay ningún movimiento independentista verdaderamente fuerte y en la cultura política americana hay un rechazo generalizado a la idea de la secesión. ${ }^{38}$ Un caso relativamente reciente en Alaska confirma esta aproximación. En el año 2006 el Tribunal Supremo de Alaska no permitió la organización de un referéndum popular sobre la independencia ya que, siguiendo su propia doctrina ${ }^{39}$ no deben autorizarse aquellas consultas populares que aborden cuestiones inconstitucionales. La pregunta que se quería plantear era la siguiente: “¿Debería el estado de Alaska obtener la independencia de los Estados Unidos y convertirse en una nación independiente si tal independencia es legalmente posible, y si tal independencia no es posible en el actual ordenamiento jurídico, debería el estado de Alaska promover cambios legales y constitucionales para autorizar dicha independencia y después obtenerla?" Según el Tribunal Supremo de Alaska el referéndum propuesto era claramente inconstitucional y, por ello, el rechazo del ejecutivo a la organización de dicha consulta fue correcto. En realidad, la discusión legal en la decisión giró, en esencia, en torno a la consolidación de la doctrina expuesta en Texas $v$. White. Así, el demandante sostuvo que no podía sostenerse su vigencia, ya que dicha sentencia fue escrita en un contexto de emociones políticas intensas. El Tribunal Supremo de Alaska contestó que tal afirmación "trivializa el impacto de la Guerra Civil en la nación americana e ignora multitud de casos del Tribunal Supremo en que se han declarado nulos los actos tendentes a la secesión de otros estados confederados." 40 Y finalizó la decisión afirmando que "cuando la bandera de cuarenta y nueve estrellas se izó por primera vez en Juneau, los habitantes de Alaska nos comprometimos con una Unión indestructible, en lo bueno y en lo malo, a perpetuidad. Sugerir lo contrario denigra el carácter republicano del gobierno nacional." ${ }^{41}$ Como se ha visto, la decisión del año 2006 en Alaska se fundamenta en los postulados esgrimidos por primera vez en Texas $v$ White, lo que confirma su vigencia.

${ }^{36}$ Radan, P. “An indestructible Union... of Indestructible States: The Supreme Court of the United States and Secession", cit., 195.

${ }^{37}$ Farber, D. (2003). Lincoln's Constitution, Chicago, The University of Chicago Press, capítulos 2 y 4.

${ }^{38}$ Lerner, C.S. (2004). "Saving the Constitution: Lincoln, Secession, and the Price of Union". Michigan Law Review, 102 (6), 1264.

${ }^{39}$ Kodiak Island Borough v. Mahoney, 71 P.3d 896 (Alaska 2003).

${ }^{40}$ Koblhaas v State, Office of Lieutenant Governor (Koblhaas I), 147 P.3d 714, 719 (Alaska 2006).

41 Ibid. 720. 


\subsection{Canadá}

La postura del constitucionalismo canadiense respecto al secesionismo quebequés ha sido calificada por López Basaguren, como se ha visto, de "nuevo paradigma". Tradicionalmente en Canadá se ha confrontado un principio federal entre las provincias (ahora 10) y la idea de dos pueblos fundadores: por un lado, los colonos francófonos, afincados en su mayoría en Quebec, y, por otro lado, los de origen anglófono, que se establecieron en otras zonas del país. La Constitución reconoce la pervivencia de ordenamientos jurídicos distintos y la promoción de dos lenguas nacionales. ${ }^{42}$ Por ello se ha justificado una posición relevante del principio federal en el constitucionalismo canadiense: es el principio que permite reconciliar la diversidad y la unidad. Al menos desde la British North America Act de 1867 en el sistema federal canadiense, más allá del diseño constitucional, ciertas normas y convenciones garantizan un estatus especial de Quebec.

Como explica Gaudreault-DesBiens, el nacionalismo quebequés ha de entenderse como la reacción de una población francófona que se siente marginada social y económicamente tanto en su propia provincia (por la élite anglófona, una minoría que ocupaba, casi en exclusiva, los puestos más relevantes dentro de la sociedad quebequesa) como en el resto del país. La situación de precariedad combinada con unas características religiosas y lingüísticas singulares promueve el desarrollo de un movimiento quebequés separatista desde finales de la década de los años cincuenta. ${ }^{43}$

El gobierno de Quebec organizó en 1980 y 1995 dos referéndums sobre la soberanía de la provincia. La organización de dichos referéndums se ajustaba a las competencias de Quebec y, por tanto, se pudieron celebrar sin ninguna oposición por parte del gobierno central. Hay que hacer notar, sin embargo, que en el constitucionalismo canadiense los referéndums no tienen efecto vinculante, extremo que deriva del principio de supremacía parlamentaria heredado del Reino Unido. ${ }^{44}$

Las cuestiones que se plantearon a los quebequeses no abordaban claramente la cuestión de la independencia de Quebec, sin embargo fueron leídas de esta manera tanto dentro como fuera del país. Tras las negociaciones políticas fallidas del Lago

42 Oliver, P. (2000), “Canada's Two Solitudes”, en Tierney, S. (ed), Accommodating National Identity. New Approaches in International and Domestic Law, London, Kluwer Law International, 65.

${ }^{43}$ Gaudreault-DesBiens, J.F. (2019) "The Law and Politics of Secession: From the Political Contingency of Secession to a "Right to Decide"? Can Lessons Be Learned from the Quebec Case?", en Delledonne, G. y Martinico, G. (eds), The Canadian Contribution to a Comparative Law of Secession, London, Palgrave, 48. El mismo autor había publicado una versión anterior en castellano. Ver GaudreaultDesBiens, J.F. (2016). "Algunos de los desafíos legales y políticos que debe afrontar el movimiento de independencia de Quebec”. Teoría y Realidad Constitucional, 37, 135-162. Ver también Blais, A. y Nadeau, R. (1992). “To be or not to be sovereignist: Quebeckers' perennial dilemma”. Canadian Public Policy/Analyse de politiques, XVIII (1), 96 y Dion, S. (1996). "Why is Secession Difficult in WellEstablished Democracies? Lessons from Quebec”. British journal of Political Science, 26 (2), 279.

${ }^{4}$ Gaudreault-DesBiens, J.F. "The Law and Politics of Secession: From the Political Contingency of Secession to a "Right to Decide"? Can Lessons Be Learned from the Quebec Case?", cit., 35.

N.o 106, septiembre-diciembre 2019, págs 105-135 
Meech, de 1987, y de Charlottetown, de 1992, tendentes a una reforma constitucional, ${ }^{45}$ y después del ajustado resultado del referéndum de 1995 (apenas 50.000 votos separaban la opción del Sí de la del No), el gobierno canadiense solicitó un dictamen al Tribunal Supremo con el fin de que se pronunciara, desde un punto de vista constitucional y de derecho internacional, sobre la demanda secesionista.

\section{2.a) Dictamen del Tribunal Supremo de Canadá sobre la aspiración de independencia de Quebec}

El dictamen no sólo se convirtió en uno de los más importantes de la historia constitucional canadiense, sino que también ha ejercido una influencia decisiva en el constitucionalismo comparado. ${ }^{46}$ Fasone sostiene que el dictamen se ha erigido en el obligado punto de partida en Europa a la hora de abordar las demandas secesionistas. ${ }^{47}$ Tal y como recuerda Martinico, fue una opinión crucial, porque el Tribunal se enfrenta de manera frontal con la secesión, yendo más allá de una lectura formal de los textos constitucionales. ${ }^{48} \mathrm{Y}$ es por ello por lo que significó un punto y aparte en el derecho constitucional comparado. Como dice Palermo, "hasta entonces, el pensamiento constitucional mayoritario asumía que las constituciones están basadas en un principio inherente de auto-preservación." ${ }^{49}$ En efecto, aunque el dictamen admitía que no hay una cláusula constitucional que regule la secesión y rechazaba el derecho

45 Hogg, P.W. (1998). Meech Lake Constitutional Accord annotated, Toronto, Carswell y Cairns, A.C. (1995). “The Charlottetown Accord: multinational Canada vs. Federalism”, en Williams, D.E. (ed), Reconfigurations: Canadian Citizenship and Constitutional Change - Selected Essays by Alan C. Cairns, Toronto, McClelland and Stewart.

46 En concreto, sobre el impacto del dictamen en España, ver el reciente trabajo de Castellà Andreu, J.M. (2019). "20 años del Dictamen del Tribunal Supremo de Canadá sobre la secesión de Quebec: su recepción en España” en Aragón Reyes et altri (dirs), cit., 289-306. Sobre la influencia en el referéndum de independencia del año 2006 en Montenegro, Oklopcic, Z. (2014). "Independence referendums and democratic theory in Quebec and Montenegro”, en Qvortrup, M. (ed), Nationalism, Referendums and Democracy. Voting on Ethic Issues and Independence, Abingdon, Routledge, 28. Una decisión reciente del Tribunal Supremo de Sri Lanka, de 8 de agosto de 2017, contiene también referencias explícitas al dictamen y asume la distinción entre autodeterminación externa e interna que se recoge en la opinión canadiense. Welikala, A. (2017). "More than meets the eye? The Sri Lankan Supreme Court's decision on the proscription of the Federal Party". Constitutionnet, 29 de agosto. http://constitutionnet.org/news/ more-meets-eye-sri-lankan-supreme-courts-decision-proscription-federal-party? utm content $=$ buffer9db34\&utm_medium $=$ social\&utm_source $=$ twitter.com\&utm_campaign =buffer

47 Fasone, C. (2019) "Canada as an "importer" and as an "exporter" of federal arrangements: A view from Europe”. DPCE Online, 38 (1), 670. http://www.dpceonline.it/index.php/dpceonline/article/ view/688

48 Martinico, G. (2019). “'A Message of Hope”: A Legal Perspective on the Reference” en Delledonne, G. y Martinico, G. (eds), The Canadian Contribution to a Comparative Law of Secession, London, Palgrave, 249.

49 Palermo, F. (2019). “Towards a Comparative Constitutional Law of Secession?” en Delledonne, G. y Martinico, G. (eds), cit., 265. 
de Quebec a una secesión unilateral tanto desde el punto de vista constitucional canadiense como desde el punto de vista de derecho internacional público, al mismo tiempo también establecía que la secesión de una provincia debía permitirse por la vía de la reforma constitucional. ${ }^{50}$

Con todo, el Tribunal no se detuvo ahí. Identificó cuatro principios constitucionales implícitos que dotaban de contenido al constitucionalismo canadiense: federalismo, democracia, constitucionalismo y Estado de Derecho y respeto por las minorías. ${ }^{51}$ Ello llevó al Tribunal a admitir que "[u]n rechazo claro por parte de los quebequeses del actual orden constitucional conferiría legitimidad a las demandas de secesión y colocaría al gobierno federal y a las otras provincias en la obligación de reconocer y respetar esa expresión de voluntad democrática por medio del inicio de negociaciones." 52

Para el Tribunal, un repudio claro en un referéndum necesariamente debe implicar ausencia de ambigüedad tanto en la redacción de la pregunta como en los apoyos que concite la respuesta..$^{53}$ Con esta advertencia probablemente el Tribunal estaba sugiriendo que los referéndums de 1980 y 1995 no cumplían esos estándares. ${ }^{54} \mathrm{El}$ requisito de una aprobación más amplia que por simple mayoría "se justifica en términos de establecer barreras procedimentales contra un derecho de salida excesivamente sencillo que comprometa las bases de la política en democracia." ${ }_{55}$ El Tribunal defiende una noción de democracia que no puede reducirse a la regla de la mayoría. Es decir, es necesario entender que la democracia es "un mosaico en el que la voluntad de la mayoría no puede ser tratada como un arma contra otros valores constitucionales." ${ }^{56}$

El Tribunal pudo haber optado por una prohibición clara y expresa de la secesión, pero en lugar de eso, opta por "una opinión compleja alejada de las declaraciones inequívocas que pretendía el gobierno federal." ${ }^{57}$ En efecto, con su dictamen el Tri-

50 Reference re Secession of Quebec, cit., para 84.

51 "Estos principios definitorios funcionan en simbiosis. Ninguno puede definirse de manera aislada, ninguno prevalece o excluye a otro." Ibid. para 49.

52 Ibid. para 88 .

53 Ibid. para 87.

${ }_{4}$ Pavkovic, A. y Radan, P. Creating New States, cit., 228. Ver también Gaudreault-DesBiens, J.F. "The Law and Politics of Secession: From the Political Contingency of Secession to a "Right to Decide"? Can Lessons Be Learned from the Quebec Case?", cit., 40. En efecto, "las dos primeras preguntas de los referéndums no estaban faltas de ambigüedad, ya que ambas se referían, directa o indirectamente, a la posibilidad de renovar la asociación entre Quebec y Canadá. La razón de que se formularan así por gobiernos claramente independentistas es simple: eran conscientes de que mayoritariamente los Quebequeses preferían un federalismo renovado o una asociación similar a la que hay dentro de la UE que una separación tajante de Canadá.” Ibid. 47.

55 Moore, M. (2000). "The ethics of secession and a Normative Theory of Nationalism”. Canadian Journal of Law E Jurisprudence, 13, 247.

56 Martinico, G. “'A Message of Hope”: A Legal Perspective on the Reference”, cit., 256.

57 Tierney, S. (2012). Constitutional Referendums: The Theory and Practice of Republican Deliberation, Oxford, Oxford University Press, 143. 
bunal favorece la discusión y las negociaciones para solucionar un conflicto político. En realidad, según el dictamen, todas las partes tienen una obligación constitucional (vinculante) de negociar. El Tribunal enfatiza que "una democracia que funciona exige un proceso de discusión continuo. ${ }^{58}$ La obligación de negociar era una idea nueva en el constitucionalismo canadiense. Para el Tribunal se trata del "corolario de principios constitucionales implícitos pero fundamentales como la democracia y el federalismo." ${ }^{59}$ En la sentencia 42/2014, el Tribunal Constitucional español se refirió explícitamente al dictamen canadiense de 1998 y también urgió a las autoridades implicadas (los gobiernos central y autonómico catalán) a iniciar un diálogo político. ${ }^{60}$

Una de las dificultades de la decisión y, en concreto, al referirse a este tipo de obligaciones, radica en cómo determinar si el Tribunal "se refiere a derechos y obligaciones legales o políticos y si, en el caso de derechos y obligaciones legales estos producirán siempre consecuencias jurídicas claras. ${ }^{61}$ En efecto, en un ejercicio de contención y siendo conscientes de que este tipo de conflictos sólo se resuelven a través de la política, los jueces canadienses no quisieron especificar el contenido concreto de las obligación de negociar. El Tribunal admitió que los procesos políticos son complejos y sólo pueden ser solventados con decisiones políticas sobre las que los tribunales no tienen un papel de supervisión (siempre y cuando la política discurra dentro de los cauces procedimentales establecidos por el ordenamiento, claro está). De igual forma, dijo el Tribunal, el inicio de las negociaciones, esto es, la evaluación sobre la claridad en la pregunta y en la respuesta sólo puede estar sujeta a examen político. ${ }^{62}$ Así, podría parecer que las obligaciones inferidas de los principios constitucionales son legales, pero los detalles y su implementación se dejan enteramente a la esfera política. ${ }^{63}$ Por ejemplo, el rechazo a negociar después de una voluntad claramente expresada socavaría la legitimación de la parte negacionista a ojos de la comunidad internacional. ${ }^{64}$

Haljan nos advierte de una interpretación incorrecta pero frecuente del dictamen: según él, el Tribunal no está afirmando que una mayoría clara en favor de la secesión signifique que el Parlamento y las otras provincias deben negociar los términos de la secesión sin posibilidad de rechazarla. El Tribunal no ha reconocido el derecho a la

58 Reference re Secession of Quebec, cit., para 68.

59 Hogg, P.W. (2015). Constitutional Law of Canada, Toronto, Carswell, $5^{\text {th }}$ ed, 5-36.

60 En palabras de Ferreres Comellas, en la sentencia del Tribunal Constitucional español había un grito para que los responsables políticos asumieran la carga de negociar una solución política que evitara una profunda crisis constitucional. Siguiendo el ejemplo canadiense, el Tribunal optó por dirigirse a los diversos actores en lugar de evitar entrar a conocer del caso, lo cual, de acuerdo con su jurisprudencia hubiera resultado bastante coherente. Ferreres Comella, V. (2014). "The Spanish Constitutional Court Confronts Catalonia's "Right to Decide"” (Comment on the Judgment 42/2014)". European Constitutional Law Review, 10 (3), 579, 585.

61 Oliver, P. "Canada's Two Solitudes", cit., 80.

62 Reference re Secession of Quebec, cit., para 100.

63 Oliver, P. "Canada's Two Solitudes", cit., 80.

${ }^{64}$ Reference re Secession of Quebec, cit., para 103. 
secesión. ${ }^{65}$ En efecto, el Tribunal indica que "ninguna negociación puede ser efectiva si el resultado final de la misma, la secesión, se considera como un derecho absoluto [...] Tal conclusión desdibujaría la obligación de negociar." ${ }^{66}$ Por lo tanto, el derecho a negociar no implica automáticamente un derecho a la secesión. Así, el Tribunal "no reconoció un derecho propio a la secesión; más bien trata la secesión como una opción que puede ser tolerada sólo si se cumplen determinadas garantías." ${ }^{67}$ El Tribunal se abstuvo, además, de pronunciarse sobre las consecuencias de un eventual fracaso en las negociaciones. El derecho que confirió el Tribunal fue el de negociar de buena fe. Los resultados concretos de las negociaciones tendrán que ser decididos por los diversos actores políticos.

El razonamiento jurídico, sin embargo, no termina aquí. El Tribunal insistió en que la obligación de negociar no podía oscurecer otro principio íntimamente vinculado: el del respeto al Estado de Derecho. Así, "si las negociaciones fracasan y se produce una declaración unilateral de independencia, ésta sería ilegal de acuerdo con el orden jurídico interno." ${ }^{68}$ En efecto, en las democracias constitucionales la voluntad popular es ilegítima si se sitúa al margen de la ley, porque, como nos recuerda el Tribunal, "es la ley la que crea el marco dentro del cual se aplica la voluntad soberana." ${ }^{69}$

El Tribunal formuló una doctrina constitucional para gestionar y afrontar tensiones políticas, incluso "para facilitar las relaciones humanas"70, que se convirtió en un punto de inflexión en el debate sobre constitucionalismo y secesión, ${ }^{71}$ convirtiéndose en un ejemplo paradigmático de "migración constitucional." 72 Al cabo de dos años el gobierno canadiense trató de normativizar la obligación de negociar en la Ley de Claridad, en la que se establecían requisitos muy estrictos para iniciar las negociaciones y, sobre todo, la potestad exclusiva de las autoridades centrales para decidir sobre el cumplimiento de dichos requisitos.

En definitiva, las provincias canadienses pueden organizar referéndums de independencia cuando lo deseen, pero sólo si la pregunta carece de ambigüedad y hay una mayoría clara a favor de la independencia se genera una obligación constitucional de negociar para ambas partes dentro del respeto al Estado de Derecho.

65 Haljan, D. Constitutionalising Secession, cit., 343.

66 Reference re Secession of Quebec, cit., para 91.

${ }^{67}$ Martinico, G. “'A Message of Hope”: A Legal Perspective on the Reference”, cit., 251.

${ }^{68}$ Gaudreault-DesBiens, J.F. "The Law and Politics of Secession: From the Political Contingency of Secession to a "Right to Decide"? Can Lessons Be Learned from the Quebec Case?", cit., 54.

69 Reference re Secession of Quebec, cit., para 67

70 Leclair, J. (2019). "Legality, Legitimacy, Decisionism and Federalism: An analysis of the Supreme Court of Canada's Reasoning in Reference re Secession of Quebec, 1998” en López Basaguren, A. y Escajedo San-Epifanio, L. (eds), cit., 81.

71 Penney, J.W. (2005). "Deciding in the Heat of the Constitutional Moment". Dalbousie Law Journal, 28 (1), 221.

${ }^{72}$ Choudhry, S. (2006). "Migration as a new metaphor in comparative constitutional law", en Choudhry, S. (ed), The migration of constitutional ideas, Cambridge, Cambridge University Press. 


\section{RESPUESTAS A PROCESOS SECESIONISTAS EN EL CONTEXTO EUROPEO OCCIDENTAL}

\subsection{Reino Unido}

\section{1.a) Escocia}

El 18 de septiembre de 2014 Escocia organizó el que, hasta el momento, es el último referéndum legal de independencia en el territorio metropolitano de una democracia liberal occidental. El rechazo a la independencia se impuso claramente (55,3\% frente al 44,7\%). Sin embargo, la posible salida del Reino Unido de la Unión Europea ha vuelto a poner esta cuestión sobre la mesa. En cualquier caso, a nuestros efectos, lo relevante es examinar la respuesta flexible ofrecida por el constitucionalismo británico: en efecto, sin apenas controversias políticas, en pocos meses los gobiernos británico y escocés acordaron la celebración de un referéndum de independencia en Escocia. ${ }^{73}$

Desde la Unión entre Escocia e Inglaterra (1707), los antiguos poderes del parlamento escocés se ejercen en Londres, en el nuevo Parlamento de Westminster. ${ }^{74}$ Sin embargo, en la cultura política británica siempre ha habido una amplia aceptación del derecho de los escoceses a decidir su propio destino, como si ello estuviera implícito en el tratado internacional de $1707 . .^{75}$

Es difícil decir si son cuestiones históricas, una tradición parlamentaria casi ininterrumpida desde hace siglos, razones de pragmatismo económico o todos estos motivos de manera combinada los que explican la aproximación tan flexible y tolerante de la política británica a la posible secesión de Escocia. Incluso los oponentes a la recuperación de la autonomía de Escocia ('devolution'), como la propia Margaret Thatcher, admiten que 'como nación, [los escoceses] tienen un indudable derecho a

73 En enero de 2012 se celebró en Westminster un debate sobre el futuro constitucional de Escocia en el que Michael Moore, Secretario de Estado para Escocia, recordó que el Scottish National Party había concurrido a las elecciones de mayo de 2011 con la promesa de la convocatoria de un referéndum y dado que habían obtenido una clara mayoría absoluta, el gobierno británico, a pesar de una opinión contraria a la independencia escocesa, no se opondría a su celebración. El debate duró apenas una hora y ningún miembro del Parlamento se opuso a la celebración del referéndum. El acuerdo final sobre los términos exactos de la consulta se celebró el 15 de octubre de 2012. Aunque en el acuerdo se insiste en la celebración de un referéndum legal y justo, no hay ninguna referencia a mayorías reforzadas.

${ }^{74}$ Qvortrup, M. (2013). "The Referendum Challenge to Constitutional Sovereignty: The Case of Scotland”. Jus Politicum, 9. http://juspoliticum.com/article/The-Referendum-Challenge-toConstitutional-Sovereignty-The-Case-of-Scotland-635.html En general, ver Elliott, J.H. (2018). Catalanes y Escoceses. Unión y Discordia, Madrid, Taurus.

75 Keating, M. (2009). The Independence of Scotland. Self-government and the Shifting Politics of Union, Oxford, Oxford University Press, 81. Ver también Munro, C.R. (2000). "Scottish Devolution: Accommodating a Restless Nation”, en Tierney, S. (ed), Accommodating National Identity. New Approaches in International and Domestic Law, London, Kluwer Law International, 134. 
la autodeterminación [...] Si optan por la independencia ningún político inglés se opondrá, aunque lamentemos mucho su marcha. ${ }^{76}$

Desde el punto de vista constitucional, uno de los aspectos más interesantes fue el procedimiento concreto que se siguió para la autorización de la convocatoria. Para entenderlo, hay que tener en cuenta varias premisas que se recuerdan en la sentencia R. (Miller) v. Secretary of State for Exiting the European Union [2016] EWHC 2768 (Admin). La primera es que la Constitución del Reino Unido no se encuentra en un único documento escrito, sino que una parte se incluye en normas escritas y otra parte se contiene en convenciones y costumbres reconocidas como constitucionales por el Parlamento y por los tribunales. ${ }^{77}$ La segunda premisa es la teoría de la soberanía parlamentaria, clave para cualquier análisis de constitucionalismo británico: “el Parlamento puede, a través de la aprobación de legislación primaria, cambiar la legislación del modo en que prefiera. No hay ninguna norma superior, salvo que el Parlamento así lo disponga." 78 Así, la soberanía parlamentaria se opone a la idea tan extendida en el mundo occidental de que las democracias son gobernadas por una Constitución, norma suprema y rígida. Dicha doctrina dota al constitucionalismo británico de mucha flexibilidad.

En el análisis del proceso independentista escocés también debe tenerse en cuenta la distribución de competencias entre Westminster y Holyrood. El esquema no es federal, el Parlamento escocés es una institución 'devuelta' y no hay ninguna razón legal por la cual la autonomía escocesa no pueda ser abolida por una ley de Westminster (aunque ello sea inimaginable políticamente). ${ }^{79}$ Sin embargo, la cuestión clave no es la subordinación del Parlamento escocés, sino los límites de sus competencias, ya que algunas están "reservadas" a Westminster. De acuerdo con la Sección 20 (2) (a) de la Scotland Act, el Parlamento escocés no puede legislar sobre materias reservadas. Entre dichas materias (defensa, política exterior, política monetaria,...) se incluye la unión y la constitución. Esta restricción es significativa, porque supone que el Parlamento escocés no podría legislar sobre un referéndum de independencia. ${ }^{80}$ Esta fue la

76 Thatcher, M. (1995). The Downing Street Years, New York, HarperCollins, 624.

77 R. (Miller) v. Secretary of State for Exiting the European Union [2016] EWHC 2768 (Admin) para 18.

78 Ibid. para 20.

79 Munro, C.R. "Scottish Devolution: Accommodating a Restless Nation”, cit., 147. Se puede encontrar una posición más matizada que sin negar la única fuente de soberanía, el Parlamento británico, trasciende una lectura legal formalista para explicar la naturaleza de la constitución territorial del Reino Unido en Page, A. (2019). "Scotland in the United Kingdom: An Enduring Settlement?" en López Basaguren, A. y Escajedo San-Epifanio, L. (eds), cit., 133 y ss. y en McHarg, A. (2019). "The Future of the United Kingdom's Territorial Constitution: Can the Union surive?” en López Basaguren, A. y Escajedo San-Epifanio, L. (eds), cit. 142 y ss.

${ }^{80}$ Hay algún autor ha puesto en duda esta lectura. MacCormick, N. (2000). "Is There a Constitutional Path to Scottish Independence?” Parliamentary Affairs, 53, 725-726. Ver también Barber, N. (2012). "Scottish Independence and the Role of the United Kingdom", UK Constitutional Law Association Blog, 11 de enero. https://ukconstitutionallaw.org/2012/01/11/nick-barber-scottishindependence-and-the-role-of-the-united-kingdom/. Sin embargo, desde un punto de vista político 
lectura mantenida por el gobierno británico y aceptada por el gobierno escocés. ${ }^{81} \mathrm{~A}$ partir de ahí, desde un punto de vista legal, había dos opciones: o bien se reformaba la Scotland Act y se le transfería a Escocia la competencia para legislar sobre la cuestión o se organizaba directamente desde Westminster la convocatoria del referéndum. Se optó por la primera opción, formalizada en la Scotland Act 1998 (Modification of Schedule 5) Order 2013, que autorizaba a Escocia para legislar sobre un referéndum de independencia que debía celebrarse no más tarde del 31 de diciembre de 2014. El límite temporal no es trivial: la modificación era ad-hoc, se trataba de una delegación temporal, no una devolución general e inespecífica. Escocia sólo tendría poderes para organizar un único referéndum antes de la finalización del año 2014.

En resumen, incluso un orden jurídico tan flexible como el británico no ha permitido que Escocia disponga de un derecho unilateral a la secesión, sino que la organización del referéndum se mantiene como una competencia de Westminster. Además, incluso en el supuesto de 2014 el gobierno británico se aseguró de que la Comisión Electoral Británica fuera la encargada de la supervisión del referéndum. En estos momentos no está claro que el gobierno británico vaya a autorizar un segundo referéndum en el futuro más inmediato, a pesar de las nuevas demandas del independentismo escocés. ${ }^{82}$

\section{1.b) Irlanda del Norte}

El caso de Irlanda del Norte es otro buen ejemplo para examinar la relación entre el constitucionalismo británico y la autodeterminación y la secesión. En este caso, sin embargo, no estaríamos ante un caso de demandas independentistas, sino ante la voluntad de Irlanda del Norte de incorporarse a otro país, Irlanda. A diferencia del caso de Escocia, donde la posibilidad de organizar un referéndum depende de la voluntad de las partes (gobiernos británico y escocés), en el caso de Irlanda del Norte el gobierno británico está constitucionalmente obligado a permitir tal procedimien-

parece haber un claro consenso: el parlamento escocés no tiene la potestad para legislar sobre un referéndum de independencia.

81 UK Government (2012). “Scotland's constitutional future” https://www.gov.uk/government/ uploads/system/uploads/attachment data/file/39248/Scotlands Constitutional Future.pdf. Ver también Scottish Government (2016). "Consultation on a Draft Referendum Bill” https://consult. scotland.gov.uk/elections-and-constitutional-development-division/draft-referendum-bill/supporting documents/j456862.pdf.

82 En el mes de agosto de 2017 la primera ministra escocesa solicitó al gobierno británico el inicio de negociaciones para la organización de un segundo referéndum. Sin perjuicio de que dichas negociaciones no se hayan iniciado, conviene destacar, como subraya Skoutaris, que el gobierno escocés está reconociendo, implícitamente, que hay una obligación legal o como mínimo una convención por la cual se necesita el permiso del gobierno británico para la organización de un referéndum de secesión en Escocia. Skoutaris, N. (2017). "Territorial Differentiation in EU Law: Can Scotland and Northern Ireland Remain in the EU and/or the Single Market?”. Cambridge Yearbook of European Legal Studies, 19, 293. 
to si se cumplen determinadas condiciones. ${ }^{83}$ En efecto, el 10 de abril de 1998 se alcanzó el Acuerdo de Belfast (o Acuerdo del Viernes Santo) entre el gobierno británico y el irlandés y la mayoría de partidos políticos de Irlanda del Norte. Fue un acuerdo compuesto de dos documentos relacionados. Primero, el Acuerdo alcanzado en las negociaciones multi-partidistas. Y, segundo, el acuerdo británico irlandés. El conjunto es lo que se conoce como Acuerdo de Belfast. Mientras que el acuerdo británico irlandés es un tratado internacional, el acuerdo multi-partidista es un acuerdo político entre fuerzas políticas. ${ }^{84}$

Resulta necesario subrayar la relevancia constitucional del Acuerdo de Belfast: su contenido no puede alterarse de manera unilateral (a diferencia de la Scotland Act). Su carácter de tratado internacional le blinda de toda tentación unilateralista. La Northern Ireland Act de 1998, la equivalente a la Scotland Act, está basada en los compromisos adquiridos en el Acuerdo de Belfast. ${ }^{85}$ Dicho acuerdo es el intento de solucionar un conflicto armado (los Troubles ${ }^{86}$ ) que durante décadas segó la vida de miles de personas. ${ }^{87}$ Los negociadores fueron capaces de elaborar un acuerdo fuertemente consociativo. ${ }^{88}$ Dicho acuerdo promueve una gran coalición, el reparto del poder de manera proporcionada entre los diversos partidos dentro del gobierno, una cierta autonomía cultural (en particular en educación y lengua) y la concurrencia de vetos para asegurar a las comunidades protestante y católica que las decisiones importantes sólo se adoptarán con un consenso amplio. ${ }^{89}$

La necesidad de consensos amplios es una de las características más relevantes del sistema autonómico norirlandés y este rasgo se va a hacer notar también en la manera de abordar la autodeterminación.

${ }^{83}$ McGarry, J. (2010). "Asymmetrical Autonomy in the United Kingdom”, en Weller, M. y Nobbs, K. (eds), Asymmetric Autonomy and the Settlement of Ethnic Conflicts, Philadelphia, University of Pennsylvania Press, 148, 156.

${ }^{84}$ Un análisis legal detallado del Acuerdo de Belfast se encuentra en Morgan, A. (2000). The Belfast Agreement: a practical legal analysis, Belfast, The Belfast Press.

85 Kissane, K. (2011). New Beginnings: Constitutionalism and Democracy in Modern Ireland, Dublin, University College Dublin Press, xii-xiii. Además, en un caso especialmente relevante (Robinson v. Sec'y of State for Northern Ireland and others, 2002) el Acuerdo de Belfast fue aceptado como el marco necesario para entender e interpreter la Northern Ireland Act (1998). McEvoy, K. y Morison, J. (2002). "Beyond the "Constitutional Moment?: Law, Transition, and Peace-making in Northern Ireland". Fordham International Law Journal, 26 (4), 967.

86 Williams, P. R. y Ardalan, S. (1999). “The Northern Ireland Peace Agreement: Evolving the Principle of Self-Determination”. Leiden Journal of International Law, 12, 157.

${ }^{87}$ Horowitz, D. (2002). "Explaining the Northern Ireland Agreement: The Sources of an Unlikely Constitutional Consensus”. British Journal of Political Science, 32, 199.

${ }^{88}$ El proceso de paz se basa en la convicción de que un sistema que promueve compartir el poder ofrece el mejor marco para la resolución del conflicto. Alonso, R. (2004). "Pathways Out of Terrorism in Northern Ireland and the Basque Country: The Misrepresentation of the Irish Model". Terrorism and Political Violence, 16 (4), 706.

89 Horowitz, D. "Explaining the Northern Ireland Agreement: The Sources of an Unlikely Constitutional Consensus”, cit., 194. 
El Acuerdo de Belfast (tanto el artículo 1 del acuerdo británico irlandés y el anexo A de las cuestiones constitucionales del acuerdo multipartidista) afirma el derecho a la autodeterminación del pueblo irlandés y especifica que dicho derecho ha de ser ejercido de común acuerdo entre las partes de la isla: 1. Los participantes respaldan el compromiso hecho por los gobiernos británico e irlandés de que, en el nuevo acuerdo británico irlandés que sustituye al acuerdo anglo irlandés, ellos (i) reconocen la legitimidad de cualquier opción libremente ejercida por una mayoría del pueblo de Irlanda el Norte respecto a su estatus, tanto si prefieren continuar en la Unión con la Gran Bretaña o formar parte de una Irlanda soberana y unificada; (ii) reconocen que es prerrogativa sólo del pueblo de la isla de Irlanda, en un acuerdo que tenga lugar respectivamente en las dos partes sin impedimentos externos, ejercer su derecho a la libre determinación, sobre la base de un consentimiento libre y concurrentemente expresado, que conlleve la unidad de Irlanda, si ese es su deseo, aceptando que este derecho debe ser ejercido respetando la voluntad de la mayoría del pueblo de Irlanda del Norte..$^{90}$

El Anexo A de las cuestiones constitucionales del acuerdo multipartidista (incorporado en la Sección 1 de la Northern Ireland Act y, por tanto, constitucionalmente vinculante como parte de la Constitución del Reino Unido) señala que (1) Irlanda del Norte en su totalidad permanece como parte del Reino Unido y no dejará de serlo sin el consentimiento de una mayoría del pueblo de Irlanda del Norte votando en una consulta convocada a tales efectos de acuerdo con el Schedule 1; (2) si el deseo expresado por la mayoría en tal consulta es que Irlanda del Norte deje de ser parte del Reino Unido y pase a integrarse en una Irlanda unificada, el Secretario de Estado presentará al Parlamento tal propuesta para dar efecto a ese deseo, tal y como se ha acordado entre el gobierno de su Majestad del Reino Unido y el gobierno de Irlanda.

Resulta interesante indicar que el Schedule 1 señala que el gobierno del Reino Unido puede mediante una Orden convocar una consulta. Además, establece que el Secretario de Estado ejercerá esta competencia "si a él le parece probable que una mayoría de esos votantes [exclusivamente norirlandeses] tienen el deseo de que Irlanda del Norte deje de pertenecer al Reino Unido y pase a formar parte de una Irlanda unificada." ${ }^{91}$ Es decir, la consulta no sirve para testar la voluntad de los votantes, sino para ratificar una voluntad claramente expresada con anterioridad. De acuerdo con esta regulación, conviene subrayar dos cuestiones: la controversia sobre el demos y el aparentemente carácter unilateral de este derecho.

En primer lugar, estas cláusulas abordan la cuestión del demos, que ha sido muy discutida en Irlanda del Norte. En realidad, se trata de la cuestión que está en el corazón de todas las disputas sobre soberanía y autodeterminación, conocida local-

90 Todd, J. (2017). "Contested Constitutionalism? Northern Ireland and the British-Irish Relationship since 2010”. Parliamentary Affairs, 70 (2), 303.

91 Estas cláusulas se encuentran tanto en el Acuerdo de Belfast de 1998 como en la Northern Ireland Act de 1998. 
mente como la cuestión constitucional. ${ }^{92}$ De manera breve: ¿hay un único demos en toda la isla, tal y como siempre ha defendido el republicanismo irlandés ${ }^{93}$ o hay dos demoi separados: un demos irlandés y un demos en Irlanda del Norte? El Acuerdo de Belfast resuelve esta cuestión declarando que el pueblo de Irlanda del Norte, de manera separada, tiene derecho a decidir. Esta postura es conocida como el principio del consentimiento. Asume que la unificación de Irlanda sólo será posible con el consentimiento de la mayoría de la población de Irlanda del Norte. ${ }^{94}$ Así, reconoce la reivindicación tradicional de la comunidad protestante del Ulster: "Los protestantes del Ulster buscan el reconocimiento de lo que para ellos es un hecho inescapable de la historia, que Irlanda la constituyen dos pueblos que tienen derechos separados." 95

En segundo lugar, el derecho a retirarse del Reino Unido e integrarse en la República de Irlanda no es unilateral, en el sentido de que puede ser decidido en cualquier momento por el gobierno norirlandés. En realidad, como se ha visto, es el gobierno británico el que tiene la potestad de valorar si hay una presumible mayoría norirlandesa a favor de retirarse del Reino Unido. ${ }^{96}$ Dicha potestad, discrecional, será difícilmente revisable y enjuiciable.

En resumen, Irlanda del Norte tiene constitucionalmente reconocido un derecho a modificar su estatus quo (obligación vinculante también desde un punto de vista internacional al estar incluido en un tratado internacional), sin embargo, tal derecho será controlado y en parte ejercido por el gobierno británico.

\subsection{Italia y Alemania}

Ni Italia ni Alemania han sufrido crisis secesionistas comparables a España, sin embargo, sí ha habido oportunidad de que sus Tribunales constitucionales se pronunciaran respecto a la secesión. En el caso de Italia, la Corte Constitucional se ha expresado en términos más restrictivos a como lo ha hecho el Alto Tribunal español. En junio de 2014, la Asamblea regional del Véneto aprobó dos leyes (15/2014 y 16/2014) sobre referéndums consultivos para (i) la mejora de la autonomía del Véneto y (ii) la independencia de la región. Ambas leyes fueron inmediatamente recurridas

92 Aughey, A. (2012). "Northern Ireland narratives of British democracy". Policy Studies, 33 (2), 147.

93 A lo largo de la historia, tanto el IRA como el Sinn Fein rechazaron que Irlanda del Norte dispusiera de un derecho a la autodeterminación autónomo y separado del resto de Irlanda. Alonso, R. "Pathways Out of Terrorism in Northern Ireland and the Basque Country: The Misrepresentation of the Irish Model”, cit., 700.

94 Ibid. 700.

95 Johnston, A.M. (1990). "Self-determination in comparative perspective: Northern Ireland and South Africa”. Politikon: South African Journal of Political Studies, 17 (2), 8.

96 Tal y como señala Qvortrup, "una de las cuestiones más persistentes y controvertidas sobre la autodeterminación y los referéndums es quién tiene derecho a iniciar la votación.” Qvortrup, M. "The Referendum Challenge to Constitutional Sovereignty: The Case of Scotland", cit. El Secretario de Estado británico tiene un papel similar al de la Cámara de los Comunes canadiense cuando ha de verificar (aunque en este caso a posteriori) la existencia de una mayoría clara en un referéndum de secesión. 
ante la Corte Constitucional por el gobierno central. En abril de 2015 la Corte Constitucional emitió una sentencia conjunta. ${ }^{97}$ El razonamiento de la Corte sobre la Ley regional del Véneto 16/2014, de 19 de junio, en virtud de la cual se convocaba un referéndum de independencia, ${ }^{98}$ que fue declarada inconstitucional, es particularmente interesante. En primer lugar, la Corte señala que "es un error asegurar que un referéndum consultivo es equivalente a cualquier muestra espontánea del derecho a la libertad de expresión ejercido por los ciudadanos de manera coordenada." (§ 5) Y ello es así, porque la Corte considera que, aunque no haya efectos jurídicos inmediatos, un referéndum desempeña una función de activar, iniciar o dificultar procesos de toma de decisiones. Es por esta razón que los referéndums, ya sean a nivel nacional o regional, incluyendo los consultivos, son "instituciones tipificadas" y han de ejercerse de acuerdo a lo fijado por las leyes y especialmente respetando límites constitucionales. (§ 5)

En definitiva, un referéndum no es una encuesta o una manifestación de democracia participativa (posición compartida por el constitucionalismo británico en el modo de aproximarse a Irlanda del Norte), sino que implica mucho más.

La Corte también rechazó el argumento de que los principios constitucionales de pluralismo y autonomía justifican "iniciativas que implican consultar al electorado sobre la posibilidad de la secesión.” (§ 7.2) Además, un referéndum sobre la independencia implica decisiones fundamentales a nivel constitucional, las cuales están excluidas de los referéndums regionales, ya que son incompatibles con los principios fundacionales de unidad e indivisibilidad de la República establecidos en el artículo 5 de la Constitución. Es más, el Tribunal sostiene que "la unidad de la República es un aspecto de derecho constitucional tan esencial que ha de ser protegido incluso contra el poder de reforma (ver sentencia 1146/1998)" (\$ 7.2).

Así, de manera implícita la Corte nos recuerda la distinción entre autonomía (atribuida a las regiones) y soberanía ${ }^{99}$ (perteneciente al pueblo italiano en su conjunto). También afirma que un referéndum sobre secesión es revolucionario en el sentido de que reta la soberanía estatal. ${ }^{100}$ Además, a diferencia de España, ${ }^{101}$ la Corte Cons-

97 Sentencia del Tribunal Constitucional 118/2015, de 29 de abril.

98 Esa ley incluía la convocatoria de un referéndum consultivo para conocer los deseos de los votantes del Véneto respecto a la siguiente cuestión: "Quiere que el Véneto se convierta en una República independiente y soberana? Sí o No?."

99 Arzoz, X. y Suksi, M. (2018). "Comparing constitutional adjudication of self-determination claims". Maastricht Journal of European and Comparative Law, 25 (4), 457.

100 Se ha considerado "un ataque directo a la unidad e indivisibilidad de la República Italiana". Fasone, C. (2015). "'Italian-style” secession and the semi-indifference of national politics”. Verfassungsblog, 21 de abril. https://verfassungsblog.de/italian-style-secession-and-the-semi-indifference-of-nationalpolitics/

101 Así, STC 42/2014. Sin embargo, también hay doctrina en España que critica esta posición. Así, Ruipérez Alamillo rechaza la posibilidad de incluir una cláusula de secesión en una hipotética reforma constitucional, ya que considera que la unidad del país operaría como límite inmanente e implícito de la reforma. Ruipérez Alamillo, J. (2013). "La nueva reivindicación de la secesión de Cataluña en el 
titucional italiana considera que hay límites implícitos en el proceso de reforma constitucional y que uno de esos límites es la integridad territorial del país. Tal y como señala Martinico, la Corte Constitucional italiana es más radical que la española. ${ }^{102}$ Esta visión restrictiva también se encuentra, aunque con matices, en el Tribunal Constitucional Federal alemán.

Un caso reciente en Alemania sirve para ilustrar que la interpretación alemana sobre la secesión dentro de un orden constitucional liberal guarda parecidos con la española y la italiana. ${ }^{103}$

El 16 de diciembre de 2016, el Tribunal Constitucional alemán consideró inadmisible un recurso presentado por un ciudadano bávaro en que solicitaba permiso para organizar un referéndum de secesión en el Land, permiso que el gobierno bávaro había denegado. ${ }^{104}$ El Tribunal emitió una breve pero categórica declaración (tres frases) afirmando que "en la República Federal de Alemania, que es un Estado nación basado en el poder constituyente del pueblo alemán, los Länder no son señores de la Constitución. ${ }^{105}$ De ahí que no haya opción para que de manera individual los Länder intenten separarse de la Federación. Estarían infringiendo el orden constitucional."

Más allá de la declaración del Tribunal Constitucional, se puede inferir de la Ley Fundamental de Bonn que el constitucionalismo alemán no reconoce ningún derecho o procedimiento de secesión, lo cual está en línea con la historia constitucional del país. ${ }^{106}$ Ello además concuerda con el principio de lealtad federal o deber de los Länder de mantener una postura leal, constructiva y positiva frente al Estado y del Bund en relación con los Länder. ${ }^{107}$ Por último, el preámbulo de la Ley Fundamental clara-

contesto normativo de la Constitución española de 1978 y el Tratado de Lisboa“. Teoría y Realidad Constitucional, 31 (89) 131.

102 Martinico, G. (2017). "Identity conflicts and secession before Courts: Three case Studies". Revista General de Derecho Público Comparado, 21, 27. La Corte Constitucional ya se había enfrentado a situaciones parecidas en el pasado. Así, en las sentencias 470/1992 y 496/2000 el Alto Tribunal ya había establecido los principios que fueron reiterados en el 2015, esto es, que en cuestiones fundamentales que atañen a todo el cuerpo electoral, es éste y no una parte quien debe decidir. Fasone, C. "Italian-style” secession and the semi-indifference of national politics", cit.

103 Ragone subraya que los tres órdenes jurídicos pueden ser comparados en el sentido de que todos tienen Constituciones rígidas que no prevén la secesión. Ragone, S. (2018). "Los Länder no son "señores de la Constitución”: el Tribunal Constitucional Federal Alemán sobre el referéndum separatista bávaro”. Teoría y Realidad Constitucional, 41, 417.

104 Decisión disponible en alemán: http://www.bundesverfassungsgericht.de/SharedDocs/ Entscheidungen/DE/2016/12/rk20161216 2bvr034916.html.

${ }^{105}$ La expresión "señores de la Constitución” es típica del constitucionalismo alemán. Montilla Martos, J.A. (2016). "The independence referendum in Germany". Instituto de Derecho Público, 16 de diciembre. http://idpbarcelona.net/docs/blog/referendum_germany.pdf.

106 Ragone, S. "Los Länder no son "señores de la Constitución”: el Tribunal Constitucional Federal Alemán sobre el referéndum separatista bávaro”, cit., 412.

107 Sosa Wagner, F. (2017). "Bávaros y Referéndum por la independencia”. Revista de Administración Pública, 202, 164. 
mente indica que el poder constituyente radica en el pueblo alemán en su conjunto, lo que también apoya esta interpretación restrictiva de la cuestión.

Resulta incierto si en caso de reforma constitucional se permitiría, como se admite en el caso español, introducir una cláusula de secesión o tal posibilidad está implícitamente excluida, como en el caso italiano. En este sentido, hay que destacar que la integridad territorial del país no está incluida en la cláusula inmanente del artículo 79.3 de la Ley Fundamental. Esta cláusula establece que cualquier reforma que afecta a la organización federal del Estado, la protección de la dignidad humana y a la definición del Estado como democrático y social será inadmisible. Así, en principio, la secesión podría incluirse en una hipotética reforma, dado que, si la integridad territorial del Estado no está incluida entre las instituciones inmunes al poder de reforma, habiendo una cláusula que establece determinados límites a dicho poder, ello significaría que la secesión debe poder discutirse en un proceso de reforma constitucional.

\section{CONCLUSIONES}

El derecho constitucional ofrece diferentes aproximaciones a la secesión, aunque con algunas perspectivas comunes. Los ordenamientos constitucionales tienden a ser muy restrictivos con las cláusulas de secesión, tal y como recordaba la Comisión de Venecia en el año 2014 a raíz del caso de Crimea: "si la Constitución ucraniana no permite un referéndum de secesión, ello no contradice en nada los estándares europeos. Es más, resulta propio de las Constituciones del Consejo de Europa prohibir la secesión." ${ }^{108}$ Tierney, de manera correcta, ha apuntado que "el mismo acto de celebrar un referéndum constitucional es en sí mismo tanto una declaración de que un pueblo existe como la definición de dicho pueblo"109 y que la celebración de este tipo de referéndums puede tener un impacto en la construcción de la nación. ${ }^{110}$ Este recelo, en parte, explica la posición restrictiva de algunos ordenamientos jurídicos europeos frente a este tipo de consultas. Los ordenamientos constitucionales de España, Italia y Alemania son una buena prueba de ello. Es por ello que al inicio se señalaba que, aunque el ejemplo español sea paradigmático, en ningún caso resulta excepcional. En

108 Comisión de Venecia "Opinion on Whether the decision taken by the Supreme Council of the Autonomous Republic of Crimea in Ukraine to organise a referendum on becoming a constituent territory of the Russian Federation or restoring Crimea's 1992 Constitution is compatible with constitutional principles" CDL-AD (2014) 4. Ver también las reflexiones de Castellà Andreu sobre la Comisión de Venecia y los referéndums de secesión en Castellà Andreu, J.M. (2017). "Sobre el encaje constitucional del pretendido referendum de secesión en Cataluña” en Sáenz Royo, E. y Garrido López, C. (coords), La funcionalidad del referéndum en la democracia representativa, Valencia, Tirant lo Blanch, 145 152.

109 Tierney, S. (2009). "Constitutional Referendums: A theoretical inquiry”. The Modern Law Review, 72 (3), 374-75.

110 Ibid. 366. 
realidad, la excepcionalidad del caso español radica en "las graves y reiteradas vulneraciones de la legalidad constitucional y estatutaria” cometidas por un gobierno autonómico, lo que nos convierte "en unicum en el panorama comparado."111

Por otro lado, las posturas canadiense y británica constituyen excepciones al paradigma clásico inaugurado por los Estados Unidos. Así, calificar las interpretaciones o posturas canadienses o británicas como "nuevo paradigma" puede llevar a la creencia (errónea) de que el paradigma clásico (o, por contraposición, viejo) ha dejado de tener vigencia en la actualidad. Sin embargo, un análisis actual de secesión y constitucionalismo en las democracias constitucionales indica que en estos momentos conviven con plena vigencia dos modelos de interpretación diferente respecto a la secesión. Mientras que sigue habiendo un modelo que la rechaza de plano o que exige una costosa reforma constitucional para aceptarla, el otro modelo (tanto el canadiense como el británico) acepta que hay un derecho a negociar dicha secesión, aunque el proceso deberá en todo caso sujetarse al ordenamiento jurídico y las instituciones centrales del Estado jugarán un papel central. Es decir, incluso la flexible tradición británica (y, en parte, canadiense) rechaza un derecho unilateral a la secesión, dado que los principios democráticos deben atemperarse con otros como el Estado de Derecho y (en el caso canadiense) con la supremacía de la Constitución. ${ }^{12}$ Esta es, sin duda, la aproximación común de todas las democracias constitucionales de nuestro entorno: la sujeción de la secesión a las normas constitucionales, es decir: la sujeción de la voluntad de una mayoría al marco normativo establecido para respetar también la voluntad de las minorías.

\section{BIBLIOGRAFÍA}

Ahumada Ruiz, M.A. (2019). "La jurisprudencia de la secesión: Texas versus White en contexto” en Aragón Reyes et altri (dirs), La Constitución de los Españoles, Madrid, Fundación Giménez Abad y Centro de Estudios Políticos y Constitucionales.

Aláez Corral, B. (2015). “Constitucionalizar la secesión para armonizar la legalidad constitucional y el principio democrático en Estados territorialmente descentralizados como España”. Revista d'Estudis Autonòmics i Federals, 22, 136-183.

Alonso, R. (2004). "Pathways Out of Terrorism in Northern Ireland and the Basque Country: The Misrepresentation of the Irish Model". Terrorism and Political Violence, 16 (4), 695-713.

111 De Vergottini, G. (2019). "Referéndum y secesión”. Teoría y Realidad Constitucional, 43, 114.

112 "Parece claro afirmar que la secesión unilateral no se permite en ningún lugar”. En Arzoz, X. y Suksi, M. "Comparing constitutional adjudication of self-determination claims”, cit., 469. 
Arzoz, X. y Suksi, M. (2018). "Comparing constitutional adjudication of self-determination claims”. Maastricht Journal of European and Comparative Law, 25 (4), 452-475.

Aughey, A. (2012). "Northern Ireland narratives of British democracy". Policy Studies, 33 (2), 145-158.

BArber, N. (2012). "Scottish Independence and the Role of the United Kingdom", UK Constitutional Law Association Blog, 11 de enero.

BAsler, R.P. et al (eds). (1954). Collected Works of Abraham Lincoln, New Brunswick, Rutgers University Press, Vol. 4.

Benjamin, J.P. (1996). “The right of Secession (December 31, 1860)”, en Wakelyn, J.L. (ed), Southern Pamphlets on Secession. November 1860 - April 1861, Chapel Hill, The University of North Carolina Press.

Blais, A. y Nadeau, R. (1992). "To be or not to be sovereignist: Quebeckers' perennial dilemma”. Canadian Public Policy/Analyse de politiques, XVIII (1), 89-103.

Buchanan, A. (1998). "Democracy and Secession", en Moore, M. (ed), National Self-Determination and Secession, Oxford, Oxford University Press.

CaIrns, A.C. (1995). "The Charlottetown Accord: multinational Canada vs. Federalism”, en Williams, DE. (ed), Reconfigurations: Canadian Citizenship and Constitutional Change - Selected Essays by Alan C. Cairns, Toronto, McClelland and Stewart.

Castellà Andreu, J.M. (2017). "Sobre el encaje constitucional del pretendido referendum de secesión en Cataluña” en Sáenz Royo, E. y Garrido López, C. (coords), La funcionalidad del referéndum en la democracia representativa, Valencia, Tirant lo Blanch.

- (2019). “20 años del Dictamen del Tribunal Supremo de Canadá sobre la secesión de Quebec: su recepción en España” en Aragón Reyes et altri (dirs), La Constitución de los Españoles, Madrid, Fundación Giménez Abad y Centro de Estudios Políticos y Constitucionales.

Choudhry, S. (2006). "Migration as a new metaphor in comparative constitutional law”, en Choudhry, S. (ed), The migration of constitutional ideas, Cambridge, Cambridge University Press.

Closa, C. (2017) (ed). Secession from a Member State and Withdrawal from the European Union. Troubled Membership, Cambridge, Cambridge University Press.

De Vergottini, G. (2019). “Referéndum y secesión”. Teoría y Realidad Constitucional, 43, 103-119.

Dion, S. (1996). "Why is Secession Difficult in Well-Established Democracies? Lessons from Quebec”. British journal of Political Science, 26 (2), 269-283.

Elliott, J.H. (2018). Catalanes y Escoceses. Unión y Discordia, Madrid, Taurus.

Farber, D. (2003). Lincoln's Constitution, Chicago, The University of Chicago Press.

FAsOne, C. (2015). “Italian-style” secession and the semi-indifference of national politics”. Verfassungsblog, 21 de abril. 
- (2019) "Canada as an "importer" and as an "exporter" of federal arrangements: A view from Europe”. DPCE Online, 38 (1), 643-671.

Ferreres Comella, V. (2014). "The Spanish Constitutional Court Confronts Catalonia's "Right to Decide"” (Comment on the Judgment 42/2014)". European Constitutional Law Review, 10 (3), 571-590.

Gaudreault-DesBiens, J.F. (2019) “The Law and Politics of Secession: From the Political Contingency of Secession to a "Right to Decide"? Can Lessons Be Learned from the Quebec Case?”, en Delledonne, G. y Martinico, G. (eds), The Canadian Contribution to a Comparative Law of Secession, London, Palgrave.

Haljan, D. (2014). Constitutionalising Secession, Londres, Hart.

Hirschl, R. (2005). “The question of Case Selection in Comparative Constitutional Law". American Journal of Comparative Law, 53, 125-156.

Hogg, P.W. (1998). Meech Lake Constitutional Accord annotated, Toronto, Carswell.

- (2015). Constitutional Law of Canada, Toronto, Carswell, $5^{\text {th }}$ ed.

Horowitz, D. (2002). "Explaining the Northern Ireland Agreement: The Sources of an Unlikely Constitutional Consensus". British Journal of Political Science, 32, 193-220.

Johnston, A.M. (1990). "Self-determination in comparative perspective: Northern Ireland and South Africa”. Politikon: South African Journal of Political Studies, 17 (2), 5-22.

Keating, M. (2009). The Independence of Scotland. Self-government and the Shifting Politics of Union, Oxford, Oxford University Press.

Kissane, K. (2011). New Beginnings: Constitutionalism and Democracy in Modern Ireland, Dublin, University College Dublin Press.

LeClair, J. (2019). "Legality, Legitimacy, Decisionism and Federalism: An analysis of the Supreme Court of Canada's Reasoning in Reference re Secession of Quebec, 1998” en López Basaguren, A. y Escajedo San-Epifanio, L. (eds), Claims for Secession and Federalism, Cham, Springer.

Lerner, C.S. (2004). "Saving the Constitution: Lincoln, Secession, and the Price of Union”. Michigan Law Review, 102 (6), 1263-1294.

López Basaguren, A. (2014). "Estado democrático y secesión de territorios. Un análisis comparado sobre el tratamiento democrático de las reclamaciones secesionistas”, en Arregi Aranburu, J. (ed), La Secesión de España, Madrid, Tecnos.

MacCormick, N. (2000). "Is There a Constitutional Path to Scottish Independence?" Parliamentary Affairs, 53, 721-736.

Mancini, S. (2012). "Secession and self-determination” en Michael, R. y Sajó, A. (eds), The Oxford Handbook of Comparative Constitutional Law, Oxford, Oxford University Press.

Martinico, G. (2017). "Identity conflicts and secession before Courts: Three case Studies”. Revista General de Derecho Público Comparado, 21, 1-30. 
- (2019). “'A Message of Hope”: A Legal Perspective on the Reference” en Delledonne, G. y Martinico, G. (eds), The Canadian Contribution to a Comparative Law of Secession, London, Palgrave.

McEvor, K. y Morison, J. (2002). "Beyond the "Constitutional Moment?: Law, Transition, and Peace-making in Northern Ireland”. Fordham International Law Journal, 26 (4), 961-995.

McHarg, A. (2019). "The Future of the United Kingdom's Territorial Constitution: Can the Union surive?” en López Basaguren, A. y Escajedo San-Epifanio, L. (eds), Claims for Secession and Federalism, Cham, Springer.

McGarry, J. (2010). “Asymmetrical Autonomy in the United Kingdom”, en Weller, M. y Nobbs, K. (eds), Asymmetric Autonomy and the Settlement of Ethnic Conflicts, Philadelphia, University of Pennsylvania Press.

Montilla Martos, J.A. (2016). "The independence referendum in Germany”. Instituto de Derecho Público, 16 de diciembre.

Moore, M. (2000). "The ethics of secession and a Normative Theory of Nationalism”. Canadian Journal of Law E Jurisprudence, 13, 225-250.

Morgan, A. (2000). The Belfast Agreement: a practical legal analysis, Belfast, The Belfast Press.

Munro, C.R. (2000). "Scottish Devolution: Accommodating a Restless Nation”, en Tierney, S. (ed), Accommodating National Identity. New Approaches in International and Domestic Law, London, Kluwer Law International.

Norman, W. (1998). "The Ethics of Secession as the Regulation of Secessionist Politics”, en Moore, M. (ed), National Self-Determination and Secession, Oxford, Oxford University Press.

Oкцорсіс, Z. (2014). "Independence referendums and democratic theory in Quebec and Montenegro”, en Qvortrup, M. (ed), Nationalism, Referendums and Democracy. Voting on Ethic Issues and Independence, Abingdon, Routledge.

Oliver, P. (2000), "Canada's Two Solitudes”, en Tierney, S. (ed), Accommodating National Identity. New Approaches in International and Domestic Law, London, Kluwer Law International.

Page, A. (2019). "Scotland in the United Kingdom: An Enduring Settlement?" en López Basaguren, A. y Escajedo San-Epifanio, L. (eds), Claims for Secession and Federalism, Cham, Springer.

Palermo, F. (2019). “Towards a Comparative Constitutional Law of Secession?” en Delledonne, G. y Martinico, G. (eds), The Canadian Contribution to a Comparative Law of Secession, London, Palgrave.

Paulsen, M.S. (2004). “The Civil War as Constitutional Interpretation”. University of Chicago Law Review, 71 (2), 691-727.

Pavkovic, A. and Radan, P. (2007). Creating New States, Farnharm, Ashgate.

Penney, J.W. (2005). "Deciding in the Heat of the Constitutional Moment". Dalbousie Law Journal, 28 (1), 217-260. 
Qvortrup, M. (2013). “The Referendum Challenge to Constitutional Sovereignty: The Case of Scotland”. Jus Politicum, 9.

RADAN, P. (2006). “An Indestructible Union... of Indestructible States: The Supreme Court of the United States and Secession”. Legal History, 10, 187-205.

Ragone, S. (2018). "Los Länder no son "señores de la Constitución”: el Tribunal Constitucional Federal Alemán sobre el referéndum separatista bávaro”. Teoría y Realidad Constitucional, 41, 407-418.

Ruipérez Alamillo, J. (2013). "La nueva reivindicación de la secesión de Cataluña en el contesto normativo de la Constitución española de 1978 y el Tratado de Lisboa“. Teoría y Realidad Constitucional, 31 (89), 89-135.

Ryan, E. (2019). "Secession and Federalism in the United States: Tools for Managing Regional Conflict in a Pluralist Society” en López Basaguren, A. y Escajedo San-Epifanio, L. (eds), Claims for Secession and Federalism, Cham, Springer.

Skoutaris, N. (2017). "Territorial Differentiation in EU Law: Can Scotland and Northern Ireland Remain in the EU and/or the Single Market?”. Cambridge Yearbook of European Legal Studies, 19, 287-310.

Sosa Wagner, F. (2017). "Bávaros y Referéndum por la independencia”. Revista de Administración Pública, 202, 157-167.

STRAuss, D.A. (2001) “The irrelevance of constitutional amendments". Harvard Law Review, 114 (5), 1457-1505.

Sunstein, C. (1991). "Constitutionalism and Secession". University of Chicago Law Review, 58, 633-670.

Tajadura, J. (2019). "La problemática jurídica de la secesión” en Aragón Reyes et altri (dirs), La Constitución de los Españoles, Madrid, Fundación Giménez Abad y Centro de Estudios Políticos y Constitucionales.

Thatcher, M. (1995). The Downing Street Years, New York, HarperCollins.

Tierney, S. (2009). "Constitutional Referendums: A theoretical inquiry". The Modern Law Review, 72 (3), 360-383.

- (2012). Constitutional Referendums: The Theory and Practice of Republican Deliberation, Oxford, Oxford University Press.

TodD, J. (2017). "Contested Constitutionalism? Northern Ireland and the British-Irish Relationship since 2010”. Parliamentary Affairs, 70 (2), 301-321.

Williams, P. R. y Ardalan, S. (1999). “The Northern Ireland Peace Agreement: Evolving the Principle of Self-Determination”. Leiden Journal of International Law, 12, 155-171.

Weinstock, D. (2011). "Constitutionalizing the Right to Secede". Journal of Political Philosopby, 9 (2), 182-203.

Welikala, A. (2017). "More than meets the eye? The Sri Lankan Supreme Court's decision on the proscription of the Federal Party”. Constitutionnet, 29 de agosto. 
Title:

Secession and comparative constitutionalism

\section{Summary:}

1. Introduction. 1.1 Secession and constitutionalism. 1.2 Should Constitutions include secession clauses? 2. The classic and new paradigm: United States and Canada. 2.1 United States. 2.1.a) Secesion through revolution. 2.1.b) Secession through consensus. 2.2 Canada. 2.2.a) Opinion of the Canadian Supreme Court Reference re Secession of Quebec. 3. Responses to pro-independence movements within the Western European context. 3.1 United Kingdom. 3.1.a) Scotland. 3.1.b) Northern Ireland. 3.2 Italy and Germany. 4. Concluding remarks. 5. References.

\section{Resumen:}

Este artículo examina el vínculo entre secesión y constitucionalismo en democracias constitucionales consolidadas analizando el debate entre el paradigma clásico, representado por el constitucionalismo americano, y el llamado nuevo paradigma, representado por el constitucionalismo canadiense. Mientras que la postura clásica se traduce en una interpretación muy restrictiva que prohíbe la secesión e incluso un referéndum de independencia, el nuevo paradigma intenta acomodar las demandas de secesión si hay una mayoría clara que así lo solicite. En la actualidad diversos ordenamientos jurídicos de democracias europeas se han visto forzados a responder a demandas secesionistas. Algún constitucionalismo, como el británico en el caso escocés, ha seguido el modelo del nuevo paradigma, permitiendo un referéndum de independencia en una parte del territorio nacional, aunque bajo supervisión del gobierno central y excluyendo la posibilidad de un derecho a la secesión (y un derecho a organizar referéndums de independencia) unilateral. En otros países, sin embargo, la posición del gobierno central y de los Altos Tribunales ha sido muy restrictiva. En este sentido, España es sin duda un ejemplo paradigmático, pero en ningún caso excepcional. Sentencias de la Corte Constitucional italiana y del Tribunal Constitucional alemán confirman, aunque con matices, esta posición española. En todos estos casos se ha señalado que, dado que la soberanía reside en el conjunto de ciudadanos, una parte de dicha ciudadanía no puede adoptar decisiones fundamentales que afectan a la totalidad del cuerpo electoral. Estas interpretaciones comunes muestran que el nuevo paradigma no ha venido a sustituir al clásico, sino que en la actualidad ambos conviven en democracias igualmente avanzadas. Además, el artículo también pretende resaltar que a pesar de las diferencias entre un modo de tratar la secesión y otro (paradigma clásico y nuevo), hay determinados rasgos comunes: respeto al Estado de Derecho y papel relevante de las instituciones estatales en el proceso, lo cual excluye cualquier tipo de secesión unilateral. 


\begin{abstract}
:
This article reviews the link between secession and constitutionalism among advanced constitutional democracies through the analysis of the debate between the classic paradigm, identified with US constitutionalism, and the so called new paradigm, identified with Canadian constitutionalism. While the classic approach is represented by a highly restrictive interpretation that prohibits secession (including a referendum on secession), the new paradigm attempts to accommodate pro-independence demands if there is a clear majority asking for it. Today, different legal orders from European democratic States have been forced to respond to this type of demands. British constitutionalism, for instance, when dealing with Scottish demands for independence, has followed the new paradigm, allowing for the secession referendum to take place in a geographically located part of the country, although with certain supervision by the central government and excluding a unilateral right to secede or even to organize an independence referendum. In other countries, however, the position of the central government and the Constitutional Courts have been highly restrictive. In this sense, Spain is undoubtedly a relevant example, yet it is not an exceptional case. In effect, recent decisions of the Italian and German Constitutional Courts confirm this interpretation, although with nuanced differences. In all these cases, the Courts have noted that sovereignty belongs to the (national) people as a whole and that a segment of such people cannot make fundamental choices when they do affect the whole of the citizenship. These common positions show that the new paradigm has not replaced the classic approach, but that both are equally valid for advanced democracies. Furthermore, this article also attempts to underline that despite the differences between both approaches to secession (classic and new paradigm), there are some common traits: respect for the Rule of Law and key role for the central government, which excludes the possibility of any type of unilateral secession.
\end{abstract}

\title{
Palabras clave:
}

Secesión, referéndum, constitucionalismo, democracia, Estado de Derecho.

\section{Key words:}

Secession, referendum, constitutionalism, democracy, Rule of Law. 